\title{
SUSTAINABLE CONTAMINATION. ADDRESSING THE IMPACT OF MATERIALS-LED INNOVATIONS ON HEIS TRANSFORMATION
}

\author{
E. D'Itria, E. Coira \\ POLITECNICO DI MILANO (ITALY)
}

\begin{abstract}
Today, we are witnessing the adoption of a European twin strategy that will strengthen competitiveness and create new values at the intersection of digital technologies and sustainability [1]. Europe recognize the combination of sustainability and digital technologies as the key to igniting future expansion in different sectors, on the international scenario.

In this context, the material dimension is returning to play a leading role as a vector of innovation driving a positive change [2].

Especially in the fashion design field, in the era of new materials revolution, sustainable materials are a fertile ground for experimentation. Companies are advancing on new and ecological improvements for the production of materials with hyper sustainable features supported by the digital medium. Nowadays, the choice for innovative textile solutions, is characterized by growing investment, radical experimentation, and firm commitment to sustainability [3].

This shifting mood also permeates Academia which has been contaminated, through a continuous flow of interactions and dialogue with industry, as proved by the thriving of multidisciplinary openness environments to face increasingly changing academic and professional contexts [4].
\end{abstract}

New models that strategically view the system in which they operate as the union of different parts are thriving [5]. No disconnection among Higher Education Institutions (HEIs) and industry but an open system which enhance innovations concerning transmitting knowledge, new technologies, and crossfertilization among different sectors.

This is a moment of transition which can foster opportunity to accelerate a process of sustainable conversion able to face the transformative challenges that are nurturing the debate on the future of HEls $[6,7,8]$.

Trough the analysis of a selected case study, this paper will investigate how these materials innovations are implementing collaborations between academia and industry for an exchange of knowledge and practices that bring a common advantage encouraging a shift toward a sustainable paradigm.

Keywords: Fashion design education, materials, sustainability, industrial transformation, collaboration, innovation systems.

\section{INTRODUCTION: A NEW MATERIALS REVOLUTION IN THE FASHION ECOSYSTEM}

Today, we are assisting to a fashion material revolution which is generating complex symbiotic relationships between two dimensions: sustainability and technologies.

The development of new knowledge enabled by the technology medium is nurturing a sustainable transition for innovative textile solutions that are characterized by increasing investment, disruptive experimentation, and a strong commitment to greener processes [3].

In this scenario, the digital innovation is essential for the development of sustainability: it drives new processes and ways of working which enable better use of resources and economic growth [2].

Materials technology disruptions fuel innovation and create sustainable value: they are changing the materials role thanks to advancements which are presenting new possibilities to redefine fashion matters as a uniquely multidisciplinary field of innovation and research [9].

It is, therefore, necessary enhancing fashion sustainability through materials as they are critical to this field: materials make fashion's intangible dimension real representing the physical medium that incorporates cultural, symbolic and evocative contents [10,11]. 
As reported by Bof [3], the fashion industry is beginning to exploit the potential of cross-collaboration with different productive and technological sectors in the materials design and production areas.

It is important to support these innovation dynamics that are linked to phenomena of knowledge transfer, or cross fertilization, that can determine the identification and testing of skills, design processes, and organizational models which have the ability to operate transversally to the fashion supply chain [12].

These operational models aim to establish a model of creation, design, and production which facilitate the sharing of an innovation process that can make the entire interconnected systems flourish. The management of these innovative processes implies the use of different scientific and technological knowledge and skills that require the creation of technological flows between different organizations and sectors [13].

For this reason, the management of new materials technological knowledge can be adequately carried out through phenomena of continuous learning and exchange that involve actors from HEls, as well as different players from industry as companies or organizations.

Nowadays, these sustainable contaminations can be vectors of a positive and holistic impact for academia that extend beyond HEls internal boundaries engaging external actors from different productive sectors [14].

\section{METHODOLOGY}

Considering what has been presented so far, it is clear that material innovations are implementing collaborations between academia and industry for an exchange of knowledge and practices that bring a common benefit by encouraging a shift towards a sustainable paradigm and nurture qualitative implementations that consider new production models supported by technical know-how and digital innovation.

According to this, the article aims to presents the result of an explorative study on how Fashion Design European HEls, are converging on the current sustainable transition with the support of a positive synergy with industry. Data are drawn from the knowledge reservoir produced by different research carried out by Fashion in Process research laboratory team at the Design department of Politecnico di Milano of which both authors are members of. The data were generated from subsequent research field studies $[15,16,17]$.

From the methodological point of view, the paper followed three main steps to produce iteratively knowledge: (1) a literature review on the current technological flows between academia and industry; (2) a map of the current experiences in the European HEls with the identification of best practices; (3) the systematization of the collected data to understand how the materials innovations are implementing collaborations between academia and industry for an exchange of knowledge and practices that bring a common advantage encouraging a shift toward a sustainable paradigm.

The first step, the literature review was carried out to identify the current practices, in Europe. This exploratory phase was based on existing academic literature, industry reports, and EU studies. This review identified many published sources giving an overview of the broad field of research: highlighting previous works and helping in locating the proposed paper in a larger context.

The second step started directly from the results of the previous one by mapping the current knowledge flows between academia and industry in Europe. During this further phase were identified $150 \mathrm{HEls}$, located in 23 nations of the European continent. Their composition was heterogeneous: they were all design schools working in the fashion field not only in relation to the design domain but also in the economics/ management, technology/engineering, and humanities ones. All the mapped institutions have distinguished themselves for the sustainable maturity of their practices. Among all the identified HEls, 50 were selected as best practices. All these institutions stand out for the way they are pursuing implementations of sustainable theories and practices within their system, addressing the impact of materials-led innovations on fashion HEls sustainable transformation adopting the technological dimension as support.

The last step, the systematization of the findings from literature review and mapping informed the design of a scenario representing how the current practices related to material innovations are starting synergies between academia and industry for supporting a fashion system sustainable transformation enabled by technological innovations. The outcomes express how actors in different sectors are 
fertilizing each other work through new sustainable materials-led solutions fueled by the technological innovations to positively impact the fashion system production, operations, and lifecycles.

These knowledge sharing experiences have a key role in promoting opportunities for the transformative challenges related to enhancing the sustainable future of academia [8], as well as addressing different fashion industry issues: (1) ensuring research, access and availability of alternatives to the finished raw materials that industry currently relies on [2]; (2) merge the continuous consumers' demand for products together with the necessity to minimize waste through materials experimentation [18]; and (3) using technology to foster research and development of greener alternatives as for digital-led solutions that could disrupt the current manufacturing model quickly creating complex products without specialist machinery, or using components that can hankering the wearables textiles implementing their functions [19].

\subsection{Working on materials sustainable alternatives}

Today, the production and consumption of materials are increasingly impacting the constraints placed on the Planet in almost every sector. The industry is driving profound changes in species biodiversity, land use, or impacts on climate and biogeochemical flows [20]. Developing alternative solutions that can reduce the impact of material use is necessary but complex and requires multidisciplinary systems approaches.

In the context outlined above, the universities identified by the paper act as players committed to nurturing the flow of knowledge between different sectors ensuring research, access, and availability of alternatives to the current finished raw materials.

This is happening through research and development activities that are the results of joint practices which explore the materials dimension looking for greener alternatives to the business-as-usual paradigm.

Incorporating raw material sustainability issues into fashion design practice is now necessary. This engages all the different dimensions involved: Profession, research, and education. The need to equip the designers of the future with the skills necessary to facilitate a sustainable tomorrow is becoming increasingly important, as well as collaborating with industry to implement solutions to sustainability issues into contemporary fashion design practices.

This collaboration is win-win: on the one hand, companies lack the resources and time to improve their knowledge, to imagine and experiment with alternative models, or to transform their design and sourcing practices [21]. On the other, fashion design students have access to advanced knowledge and experience sustainable design practices driven by material innovation during their education path but lack of awareness about the market "real world" [16]. Collaboration between these different stakeholders, sharing resources, knowledge and experience then becomes a valuable asset to create more sustainable design practices that impact the first two key stages of the fashion supply chain: design/creation and raw materials [17].

\subsection{Materials role in minimizing waste}

In the last years, the fashion system has adopted a widely applied industry practice that is based on the desire to offer a continuous flow of new merchandise to the market: the fast fashion [22].

This type of model is unsustainable and feeds a system of mass consumerism that sooner or later will need to end. As stated by Niinimäki [23] fashion will pay a high environmental price related to the continuous exploitation of natural resources: compared to $97 \%$ of virgin resources used every year, the fashion system returns $75 \%$ of them in the waste form that ends up in landfills or incinerated [18].

The HEls that are operating in this direction are working, together with other sectors, on developing materials solution which guided by the technological medium can balance the continuous market and consumers request with the sustainable issue of minimizing fashion waste.

This kind of collaborations are positive ones. Companies are able to obtain resources to imagine and experiment with alternative models: Transforming their own design and waste management practices. Meanwhile, the academy get access to funds and channels of communication for creating crosssectorial networks. These networks can generate virtuous synergies that allow the advancement of the fashion sector different dimensions, academic and professional, towards a more sustainable paradigm impacting on the role of waste that becomes a resource. 


\subsection{Hacking fashion matters}

Fashion Wearable Technology is a new dimension in the fashion industry that combines functionality, fashion and technology including: Smart fabrics, nanotechnology, Al, soft robotics, and engineering [24]. The goal is to design smart materials. These are adaptive materials that hack common textile materials to integrate multifunctionality beyond clothing. In this field, interdisciplinary collaborations are key to experimenting with applications to bridge the gap between academic research and product relevance [25]. Furthermore, in this field, technology is adding an opportunity to fashion sustainability by testing solutions that can impact the use and lifespan of the material itself.

In this context, cross-fertilization among HEls and industry is related to an evolving phenomenon that need to be codified ensuring an approach in line with its potential. It is necessary to educate on new forms of wearable technologies.

This is because while the technological implementation of wearables is evolving fast, their consequences have yet to be examined. These issues involve several dimensions: Social, ethical, and ecological [26]. The academy needs to investigate these issues to guide the exploration and overcoming of adoption barriers related to wearable technologies, materials, and guide the industrial path.

According to the aforementioned outcomes, the next section reports an emblematic case study, selected among the ones identified during the mapping activity, that embed the presented three aspects of how knowledge sharing experiences are boosting the sustainable transformation of academia, while addressing some of the main industry productive problems [20].

\section{THE OPEN FASHION SYSTEM MATERIAL INNOVATIONS: A CASE STUDY}

According to the above, the discourse around the flow of interactions between academia and fashion industry is fostering innovation and creating an open multidisciplinary environment for students to grow and be prepared to face an everchanging professional environment.

This is particularly true in fields such fashion, where the changeability of the market demand is per se a driver for the required adaptability of its workers. Today, to prepare new fashion designers to face the sector future challenges is necessary to propose new multidisciplinary practices.

To reach this objective of common growth and knowledge transmission, it is fundamental for companies and universities to proceed side by side in a mutual process of knowledge transmission and acquisition.

In the proposed scenario, this section presents a best practice which is a virtuous example that testify the application of the discussed principles. Coded Bodies is a learning module based on the fertile exchange between the academic world (Politecnico di Milano) and the professional dimension (Giulia Tomasello, designer). This educational activity provides future fashion designers with new skills that arise from synergies between the material and technological dimensions by experimenting with biomaterials, minimizing waste, and using technology to make wearables by implementing their functions.

\subsection{The Coded Bodies experience}

Today, HEls operate to innovate models that strategically nurture an ecosystem able to enhance industry-academy collaboration based on open innovation model that concern transmitting knowledge, new technologies, and cross-fertilization among different sectors [5].

In line with the proposed context, Politecnico di Milano is evolving its own research, as well as didactic activities. In particular, the paper analysed the Final Synthesis Design Studio called "Design for the Fashion System" [27], which is offered by the Design Department. This course has distinguished itself for its educational offering that provide students with the opportunity to explore advanced multidisciplinary knowledge in order to consolidate those design skills needed in professional contexts and ever-changing work markets.

The selected course is focused on driving innovation through design offering diverse teaching experiences: A mix of lectures, discussion-based modules, and design studio activities. This didactic structure is conceived for breaking the traditional linear semester rhythm [4]. 
The presented teaching approach is based on the workshop methodology, which has been identified by faculty as the preferred method for students to explore different areas of fashion design practice in relation to the two key dimensions that are driving the modern transformation of the industry: digital technologies and sustainability [1].

Right at the intersection of these two dimensions the course places the workshop ideated by designer Giulia Tomasello and called "Coded Bodies".

Giulia Tomasello is an Italian designer who is expert in working with biomaterials, interactive textiles and living organisms. Her experimental work focuses on the link between microorganisms and the human body, with particular attention to the female body.

In particular, the designer deals with a type of interaction that engages the living organisms of which the fabric is made and the person who wears it.

A design path that began immediately after graduating from the Material Future master's program in London. Tomasello started to work in synergy with the Biohacker Space in London, tutored by experts who helped her in giving shape to her projects $[28,29,30]$.

From this first experience of hacking materials with technology derives the Coded Bodies workshop. This is a series of activities designed for students with the purpose of introducing them to the basics of Arduino coding, soft wearables, and biological textiles. During the workshop, Giulia Tomasello introduces students to the world of wearable technologies, with a specific focus on biotechnology [25]. Approaching traditional textile techniques combined with technology and smart materials, student groups explore the potential of bacterial celluloses for future textiles in terms of growing living materials and creating speculative scenarios for second skins and sensors, to ultimately produce a working prototype in its social context. The results are relevant both in terms of technical skills acquired and mindset transformation. Through an exploratory practice derived from the field of Research \& Development, in an intersection between Industry and Academy, students are empowered to merge technical skills mixing 3D printing technologies with $\mathrm{Al}$ and biomaterials, in order to promote sustainable transition and strengthen their skills in the areas of waste minimization, ecofriendly, compostable and circular products [31].

This workshop shows how fashion is a differentiated and stratified phenomenon, which is able to merge the contemporaneity of innovative, sustainable and technologically driven production practices with a more traditional approach. Moreover, this context is enhanced and enabled by the continuous process of knowledge exchange, both in terms of theoretical and practical know-how.

The main output of Coded Bodies is the development of students' functional and sectoral transversal competencies that must deal with the intricate nature of the fashion system, which reflects the complexity of the learning environment itself. In this context, through multidisciplinary, intersectional and transversal learning activities, the student is able to achieve the skills required by the market.

The fusion of theoretical concepts with more instrumental skills and intensive design experiences are allowing future designers to face the transition from the traditional "product centred" fashion system to a more sustainable and "user centred" paradigm, maximizing the effects of the sustainable transition enabled by the digital medium [4].

\section{CONCLUSIONS}

The proposed scenario reports how European HEls are performing a sustainable transition in their systems aided by materials innovations. This paper aimed at showing through the explorative study results and presenting an emblematic example, from a world leading university, how sustainable contaminations are now happening between academia and industry addressing the impact of materials-led innovations on fashion HEls transformation.

The contribution of this paper to knowledge is twofold. Firstly, it presents a concrete example of crossfertilization initiatives, also showing how sustainable innovation can be implemented across contexts through tech-led materials innovations. Secondly, the paper shows that even though transformative approaches to enhance sustainability in the curricula are feasible and desirable [7], they require academics to develop collaborative approaches with external actors from other sectors.

This paper aims to report an evidence about sustainable transformation in HEls and the whole institutions approach involving cross-sector partnerships: fashion design HEls are successfully 
incorporating cross-sectorial contributions coming from the real world, cooperating with external players, such as companies [32].

Today, the presented contamination is already happening in some institutions, and it can be described as a positive shift from a passive teaching and learning experience to an active interaction [33].

\section{REFERENCES}

[1] European Commission - European Commission. 2021. A European Green Deal. [online] Available at: <https://ec.europa.eu/info/strategy/priorities-2019-2024/european-green-deal_en> [Accessed 11 May 2021].

[2] Reports.fashionforgood.com. 2021. [online] Available at: <https://reports.fashionforgood.com/wp-content/uploads/2020/12/Understanding-Bio-MaterialInnovations-Report.pdf> [Accessed 11 May 2021].

[3] BOF-MCKINSEY, STATE OF FASHION 2020. [online] Available at: https://www.mckinsey.com/ /media/McKinsey/lndustries/Retail/Our\%20Insights/The\%20state\% 20 of\%20fashion $\% 202020 \% 20$ Navigating \%20uncertainty/The-State-of-Fashion-2020-final.ashx [Accessed 11 May 2021].

[4] P. Bertola and A. Vandi, "EXPLORING INNOVATIVE APPROACHES TO FASHION EDUCATION THROUGH A MULTIDISCIPLINARY CONTEXT FOR NEW PROFESSIONAL PROFILES," in INTED2020 Proceedings, 2020, vol. 1, pp. 4813-4819.

[5] Gòmez-Gasquet P, Cuenca L, Boza A, Alfaro-Saiz J, Verdecho M, Vincens-Salort E, et al. "Industry-academy collaboration: an open innovation framework". In: Vacca F, Warshavski T, editors. Mandragora; 2016. p. 35-41.

[6] T. Moya, "Higher Education in the World 3: New Challenges and Emerging Roles for Human and Social Development". In Global University Network for Innovation. Higher education in the world : accreditation for quality assurance : what is the stake? 2007. pp.161-169, Basingstoke, England: Palgrave Macmillan. 2007.

[7] S. Sterling, "Transformative learning and sustainability: Sketching the conceptual ground. Learning and Teaching in Higher Education". 2011; 5:17-33.

[8] K. Fletcher and D. Williams, "Fashion Education in Sustainability in Practice," Res. J. Text. Appar., vol. 17, no. 2, pp. 81-88, 2013.

[9] B. Quinn, "Textile Futures: Fashion, Design and Technology". London, England: Berg; 2008.

[10] K. Fletcher; L. Grose; P. Hawken, "Fashion and Sustainability: Design for Change"; Laurence King: London, UK, 2012.

[11] P. Bertola, F. Vacca, C. Colombi, V.M. Iannilli, M. Augello, "The Cultural Dimension of Design Driven Innovation. A Perspective from the Fashion Industry", in The Design Journal, 2016, 19:2, 237-251, 2016.

[12] G.M. CONTI, "Cross Fertilization: un approccio al progetto per la moda." Milano : Mondadori Università, 2012.

[13] S. Black, Editorial in "Fashion Practice: Design, Creative Process and the Fahion Industry". Fashion Practice: The Journal of Design, Creative Process and the Fashion Industry, 2008, 1 (1). p. 5-8, 2008.

[14] E. D'Itria and F. Vacca, "Fashion Design for Sustainability. A transformative challenge across the European fashion education system". Forthcoming 2021.

[15] DG GROW, Study on 'Mapping sustainable fashion opportunities for SMEs', Accessed 12 May, 2021. Retrieved from https://ec.europa.eu/growth/content/study-mapping-sustainable-fashionopportunities-smes_en

[16] FashionSEEDS, Education and Research. The Benchmarking Report, Accessed 11 May 2021. Retrieved from https://www.arts.ac.uk/_data/assets/pdf_file/0022/201865/IO1-

BENCHMARKING-REPORT.pdf 
[17] E. D'Itria, "Driving Sustainable Change in Fashion" [Doctoral dissertation, Politecnico di Milano, Milan, Italy] (Unpublished).

[18] Ellen MacArthur Foundation, A new textiles economy: Redesigning fashion's future, Accessed 11 May, 2021. Retrieved from: http://www.ellenmacarthurfoundation.org/publications

[19] K. Abnett, Fashion's Fourth Industrial Revolution. 2016. Retrieved from https://www.businessoffashion.com/articles/technology/fashions-fourth-industrial-revolution-2

[20] E. A. Olivetti and J. M. Cullen, "Toward a sustainable materials system," Science, vol. 360, no. 6396. pp. 1396-1398, 2018.

[21] Y. Bakırlıoğlu and M. McMahon "Co-learning for sustainable design: The case of a circular design collaborative project in Ireland", in Journal of Cleaner Production, 279, 123474, 2021.

[22] T. M. Choi, C. L. Hui, N. Liu, S. F. Ng, and Y. Yu, "Fast fashion sales forecasting with limited data and time," Decis. Support Syst., vol. 59, no. 1, pp. 84-92, Mar. 2014.

[23] K. Niinimäki, G. Peters, H. Dahlbo, P. Perry, T. Rissanen, and A. Gwilt, "The environmental price of fast fashion," Nat. Rev. Earth Environ., vol. 1, no. 4, pp. 189-200, Apr. 2020.

[24] H. Zega "Fashion Wearable Technology", in UBT International Conference, 7, 2020.

[25] R. R. Ruckdashel, D. Venkataraman, and J. H. Park, "Smart textiles: A toolkit to fashion the future," Journal of Applied Physics, vol. 129, no. 13. p. 130903, 2021.

[26] B. Giesenbauer and G. Müller-Christ, "University 4.0: Promoting the transformation of higher education institutions toward sustainable development," Sustain., vol. 12, no. 8, 2020. Segura Anaya, L. H., Alsadoon, A., Costadopoulos, N., and Prasad, P. W. C. 2018. "Ethical Implications of User Perceptions of Wearable Devices," Science and Engineering Ethics (24:1), pp. 1-28.

[27] Politecnico di Milano, Des (Mag)(ord. 270) - BV (1097) DESIGN FOR THE FASHION SYSTEM - DESIGN PER IL SISTEMA MODA Detailed Programme, Accessed 11 May, 2021. Retrieved from:

https://www11.ceda.polimi.it/schedaincarico/schedaincarico/controller/scheda_pubblica/Scheda Public.do?\&evn_default $=$ evento\&c_classe $=745490 \& \_p j 0=0 \& \_p j 1=a 30303 \mathrm{bc} 5 \mathrm{ba} 1620 \mathrm{c} 5 \mathrm{a} 0 \mathrm{dc}$ 63d0f3a47e5.

[28] G. Tomasello, Gitomasello, Accessed 11 May, 2021. Retrieved from: https://gitomasello.com/.

[29] F. Fontana, L'EMPOWERMENT FEMMINILE PASSA DAI BATTERI. INTERVISTA CON GIULIA TOMASELLO. Accessed 10 May, 2021. Retrieved from: https://digicult.it/it/design/female-empowerment-goes-through-bacteria-an-interview-with-giuliatomasello/

[30] M. Pitino, Design sostenibile: idee per un futuro migliore. Accessed 9 May, 2021. Retrieved from: https://www.ad-italia.it/design/lifestyle/2020/05/15/design-sostenibile-idee-per-un-futuromigliore/ [Accessed April 2021]

[31] Coded Bodies, Coded Bodies, 2020. Accessed 8 May, 2021. Retrieved from: http://www.adiacenze.it/coded-bodies/.

[32] H. Etzkowitz and J. Dzisah "Rethinking development: Circulation in the triple helix", in Technology Analysis and Strategic Management, 2008.

[33] P. Bertola, V. Hillen, and R. Swearer "A new kind of university", in B. Banerjee \& S. Ceri (Eds.), Creating Innovation leaders: A global perspective. New York, NY: Springer International Publishing, 2016. 